\title{
Sociolinguistics: Quantitative Methods
}

\author{
JACK GRIEVE \\ Introduction
}

Variationist sociolinguistics was one of the first branches of linguistics to adopt a quantitative approach to data analysis (e.g., Fischer, 1958; Labov, 1963, 1966, 1969; Wolfram, 1969). While the earliest variationist studies did not usually employ statistical methods, they were concerned nonetheless with identifying a relationship between the values of a quantitative linguistic variable and the levels of a categorical social variable. The linguistic variables analyzed in traditional variationist studies represent an alternation between two distinct linguistic forms (or variants) that convey the same basic meaning (Labov, 1972; Wolfram, 1991). Examples of linguistic variables include sets of alternative pronunciations, equivalent grammatical constructions, and synonymous words. The basic goal of variationist research is to identify the social factors that influence the choice between the variants of linguistic variables. For example, Labov (1966) found that the likelihood of pronouncing / r/ following vowels was directly related to the socioeconomic status of speakers in New York City. Labov also found that the pronunciation of $/ \mathrm{r} /$ was related to age, with younger speakers being more likely to pronounce / $\mathrm{r}$ / than older speakers in the upper middle class, but with older speakers being more likely to pronounce $/ \mathrm{r} /$ than younger speakers in the lower middle class. Labov argued that the pronunciation of $/ \mathrm{r} /$ was most common in the language of the younger upper middle class because this pronunciation was in the process of becoming the more prestigious form, but that this pattern was reversed in the language of the lower middle class because older speakers were more likely to be aware of the prestige associated with the pronunciation / $\mathrm{r}$ / than younger speakers, and were thus more likely to adopt the innovation, revealing their social aspirations.

While early variationist studies focused on simple relationships between the value of a linguistic variable and the value of a social variable, over time more advanced methods for the analysis of linguistic variation were developed. Since the 1970s, the most common statistical method in sociolinguistic research has been logistic regression, which is used to test if the alternation between the variants of a linguistic variable is predicted by various aspects of the social background of a speaker, while also taking into consideration the effect of the linguistic environment in which each token of the variable is produced (Cedergren \& Sankoff, 1974; Sankoff \& Labov, 1979). For example, Ashby (1981) used a logistic regression to analyze variation in the use of the negative particle ne in French, which can optionally be deleted, as negation is marked redundantly elsewhere in the sentence. Ashby found that age, social class, and gender all affect negative-particle deletion in French, with the young, the lower middle class, and women being more likely to delete ne. Sociolinguistic research of this type has repeatedly shown that linguistic variation is correlated with numerous factors related to the social background of speakers, including age, gender, ethnicity, and socioeconomic status, as well as various linguistic factors.

While logistic regression is a standard technique in sociolinguistics, no form of regression analysis is common in regional dialectology, the precursor and now a subdiscipline of the field. Indeed, one of the main factors that led to modern sociolinguistics superseding traditional dialectology was its adoption of a statistical approach to data analysis. Traditional dialectology did not employ statistical methods, but relied instead on the subjective analysis of categorical display maps plotting where the different variants of a linguistic variable occurred across a region (e.g., Wenker, 1881; Gilliéron, 1902-10; Kurath, Hansen, Bloch, \& Bloch, 1939-43; Kurath, 1949; Kurath \& McDavid, 1961). Modern American dialectology 


\section{SOCIOLINGUISTICS: QUANTITATIVE METHODS}

(e.g., Pederson, McDaniel, \& Adams, 1986-93; Carver, 1987; Labov, Ash, \& Boberg, 2006) is still largely based on subjective approaches to data analysis; basic statistics are computed, but the identification of regional patterns is still based primarily on the judgment of dialectologists. In European dialectology, a quantitative approach known as dialectometry (Séguy, 1971, 1973; Goebl, 1982, 2006; Nerbonne et al., 1996; Nerbonne \& Kleiweg, 2003, 2007) has become common, but it involves initially aggregating the values of numerous linguistic variables and thus offers no direct method for testing if an individual linguistic variable exhibits a regional pattern, in the way that logistic regression allows for social patterns to be identified in the distribution of a linguistic variable. The reason that regression has not become a standard tool in regional dialectology is because regional linguistic patterns are not necessarily linear. A linear pattern is possible, such as the gradual change in the value of a linguistic variable from the southwest to the northeast of a region; however, non-linear patterns are also possible, such as the clustering of a variant in the center of a region or the presence of numerous smaller clusters across a region. While linear regional patterns could be identified in the distribution of a linguistic variable by conducting a regression with longitude and latitude as predictors, non-linear patterns, which seem to abound in regional dialectology, cannot be easily identified using any form of linear regression.

This entry presents a solution to this problem - a quantitative method for identifying significant linear and non-linear regional patterns in the values of an individual linguistic variable measured across a series of locations. The method is based on two measures of spatial autocorrelation: global Moran's I and local Getis-Ord Gi*. These statistics allow for significant regional clusters to be identified in the spatial distribution of a linguistic variable. Moran's I identifies variables that exhibit significant levels of spatial clustering, while Getis-Ord Gi* identifies the location of high- and low-value clusters. These statistics are used here to test if four measures of not contraction are regionally patterned in a corpus of letters to the editor representing the language of 200 cities from across the United States. In addition to illustrating the use of these statistics, this study also demonstrates that regional linguistic variation exists in written Standard American English. This is an important finding in and of itself, as it is generally assumed that regional linguistic variation, and sociolinguistic variation in general, does not exist to a significant degree in the written standard, but only in writing that directly represents the spoken vernacular (Schneider, 2002).

\section{Data Collection}

This study is based on a corpus of letters to the editor representing the language of 200 cities from across the United States. The letter-to-the-editor register was selected for analysis because it is a variety of written Standard English that is particularly suitable for a study of regional linguistic variation: Letters to the editor are annotated for their author's place of residence, written by a large number of authors from across the United States, published frequently, and made freely available online. The corpus of letters to the editor was compiled by downloading letters published between 2000 and 2008 from the online archives of hundreds of American newspapers. Once downloaded, each letter was sorted into a city subcorpus based on its author's place of residence, as indicated in the byline of the letter. City subcorpora were then formed for the 200 cities whose residents had contributed at least 25,000 words of text. The corpus includes cities in every state in the contiguous United States, including most major cities. The entire corpus contains 154,269 letters written by 126,422 authors totalling 25,794,656 words. 


\section{Data Analysis}

Four measures of not contraction were analyzed across the 200 city subcorpora: not contraction following copular and auxiliary be (e.g., he is not/isn't there), auxiliary have (e.g., he has not/hasn't spoken), auxiliary do (e.g., he does not/doesn't mind), and modals (e.g., he will not/won't mind). The variables were computed by calculating the proportion of contracted not relative to full not-see Equation 1, where $f_{\text {cont }}$ is the frequency of the contracted form and $f_{\text {full }}$ is the frequency of the full form.

$$
\text { (1) } v=\frac{f_{\text {cont }}}{f_{\text {cont }}+f_{\text {full }}}
$$

Each contraction variable was measured in this way for each city subcorpus.

In order to determine if each measure of not contraction exhibits a significant regional pattern, each variable was subjected to an analysis of spatial autocorrelation-a measure of spatial dependency that quantifies the degree of spatial clustering in the values of a variable (Cliff \& Ord, 1973, 1981; Odland, 1988). First, an analysis of global spatial autocorrelation was conducted using global Moran's I (Moran, 1948; Odland, 1988). The value of Moran's I ranges from -1 to 1 , where a negative value indicates that neighboring data points tend to have different values, a value approaching zero indicates that neighboring data points tend to have random values, and a positive value indicates that neighboring data points tend to have similar values (Odland, 1988). The formula for calculating global Moran's $I$ is provided in Equation 2 (Odland, 1988), where $N$ is the total number of locations, $x_{i}$ is value of the variable at location $i, x_{j}$ is value of the variable at location $j, \bar{x}$ is the mean for the variable across all locations, and $w_{i j}$ is the value of the spatial weighting function for the comparison of location $x_{i}$ and $x_{j}$.

$$
\text { (2) } I=\frac{N}{\sum_{i} \sum_{j} w_{i j}} \frac{\sum_{i} \sum_{j} w_{i j}\left(x_{i}-\bar{x}\right)\left(x_{j}-\bar{x}\right)}{\sum_{i}\left(x_{i}-\bar{x}\right)^{2}}
$$

The spatial weighting function is a set of rules that assigns a weight to every pair of values in the distribution of a variable based on proximity. In this study, a standard binary weighting function with a 500-mile cutoff distance was used, so that comparisons between locations within 500 miles of each other were given a weight of 1 and all other comparisons were given a weight of 0 . A 500-mile radius was selected so that locations traditionally classified as being within the same dialect and cultural regions could be compared. In order to determine the significance of the computed value for Moran's I, a standardized $z$ score was obtained, under the assumption of randomization (see Odland, 1988). The $z$ score was then interpreted as significant if it was larger than or equal to 2.50 - the $z$ score corresponding to a two-tailed .0125 alpha level, which was selected based on a Bonferroni correction for four variables. A significant positive $z$ score indicates that neighboring locations have similar values at a greater degree than would be expected by chance.

In addition to measuring global spatial autocorrelation, which tests whether a variable is regionally patterned, local spatial autocorrelation was measured in order to identify the location of high- and low-value clusters in the spatial distribution of each variable. Local spatial autocorrelation was measured using local Getis-Ord Gi* (Ord \& Getis, 1995). Unlike global Moran's $I$, which returns one value for a variable indicating the degree of regional clustering, local Getis-Ord $G i^{*}$ returns a $z$ score for each location for a variable indicating the degree to which that location is part of a high- or low-value cluster. The formula for calculating a Getis-Ord $\mathrm{Gi}^{*} z$ score is provided in Equation 3 (Ord \& Getis, 1995). 
(3) $G_{i}^{*}=\frac{\sum_{j} w_{i j} x_{j}-\bar{x} \sum_{j} w_{i j}}{\sqrt{\frac{\sum_{j} x_{j}^{2}}{N}-\bar{x}^{2}} \sqrt{\frac{N \sum_{j} w_{i j}^{2}-\left(\sum_{j} w_{i j}\right)^{2}}{N-1}}}$

A significant negative Getis-Ord $G i^{*} z$ score indicates that the location is part of a low-value cluster, whereas a significant positive Getis-Ord $G i^{*} z$ score indicates that the location is part of a high-value cluster. The Getis-Ord $G i^{*} z$ score was interpreted as significant if it was larger than or equal to 2.50, based on the Bonferroni correction described above. Once computed, the Getis-Ord $\mathrm{Gi}^{*} z$ scores for each variable were then mapped in order to identify the location of significant high- and low-value clusters.

\section{Results}

Based on the analysis of global spatial autocorrelation, significant clustering was identified for three of the four measures of not contraction: be not contraction $(I=0.039, p=0.001)$, do not contraction $(I=0.077, p=0.000)$, and modal not contraction $(I=0.050, p=0.000)$. Based on the adjusted $p$ value, have not contraction was not found to exhibit significant levels of clustering $(I=0.024, p=0.033)$. Maps displaying the corresponding Getis-Ord $\mathrm{Gi}^{*} z$ scores for the three measures of not contraction found to exhibit significant levels of global spatial autocorrelation are presented in Figures 1-3. These maps identify the location of high- and low-value clusters in the distributions of the individual variables. Based on an analysis of these local spatial autocorrelation maps, it is clear that all three variables exhibit similar regional patterns, contrasting the language of the East Coast, where not contraction is relatively uncommon, with the language of the rest of the United States, where not contraction is relatively common. However, while the low values for all three

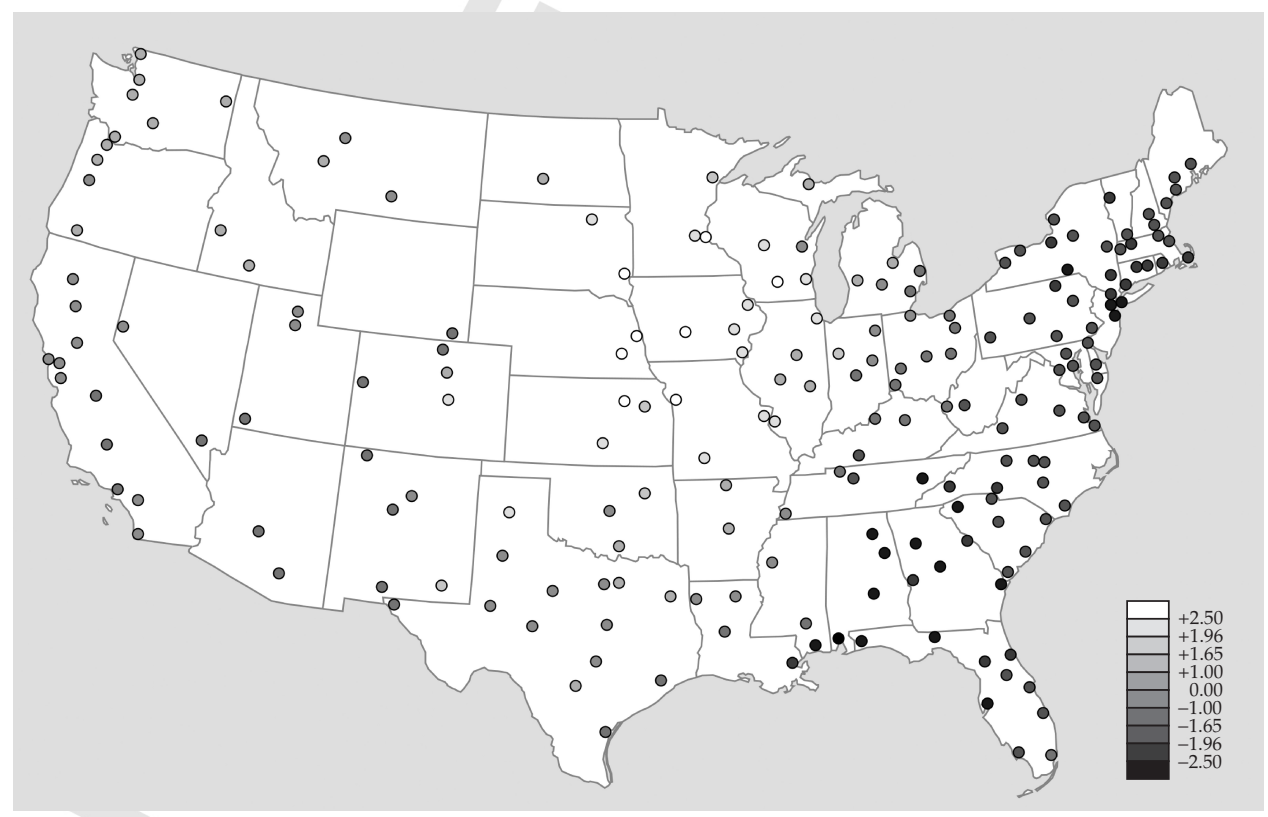

Figure 1 Be not contraction Getis-Ord $G i^{*} z$ scores 


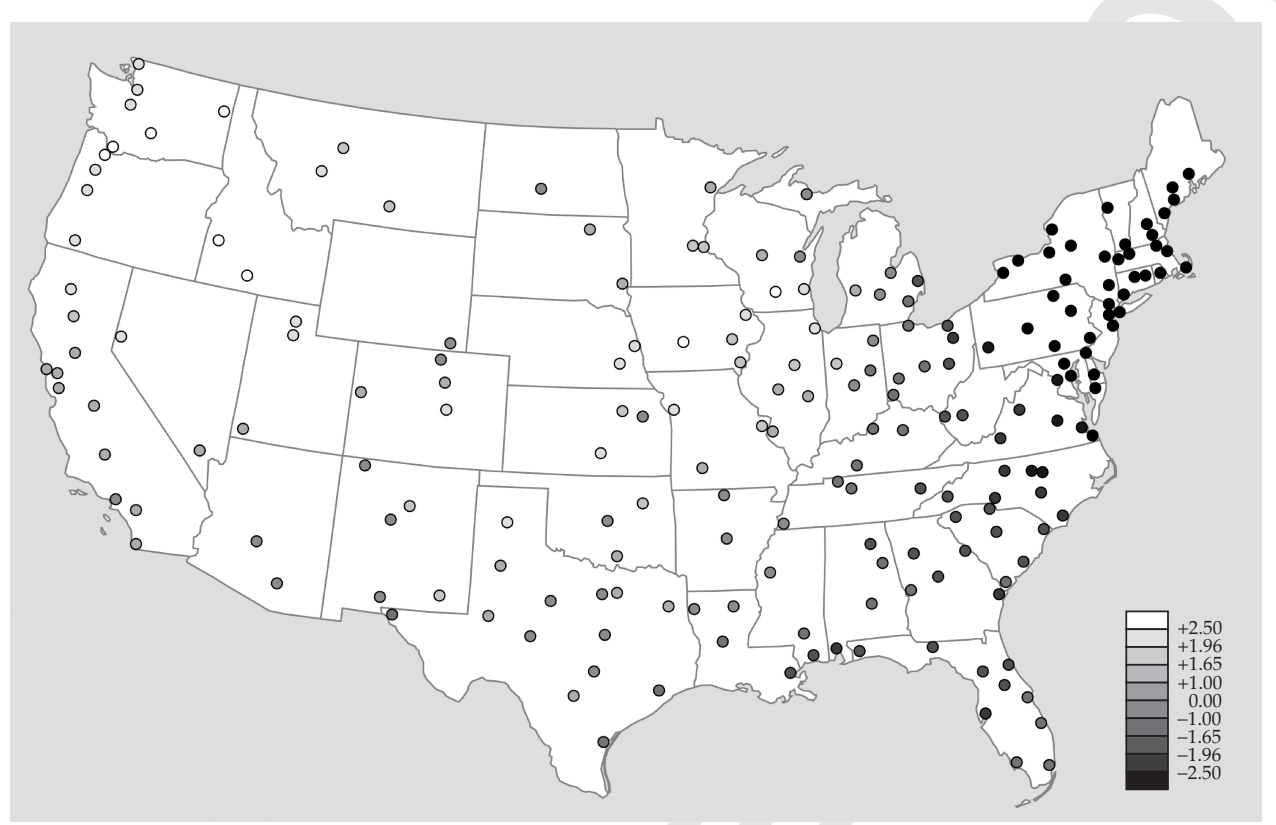

Figure 2 Do not contraction Getis-Ord $\mathrm{Gi}^{*} z$ scores

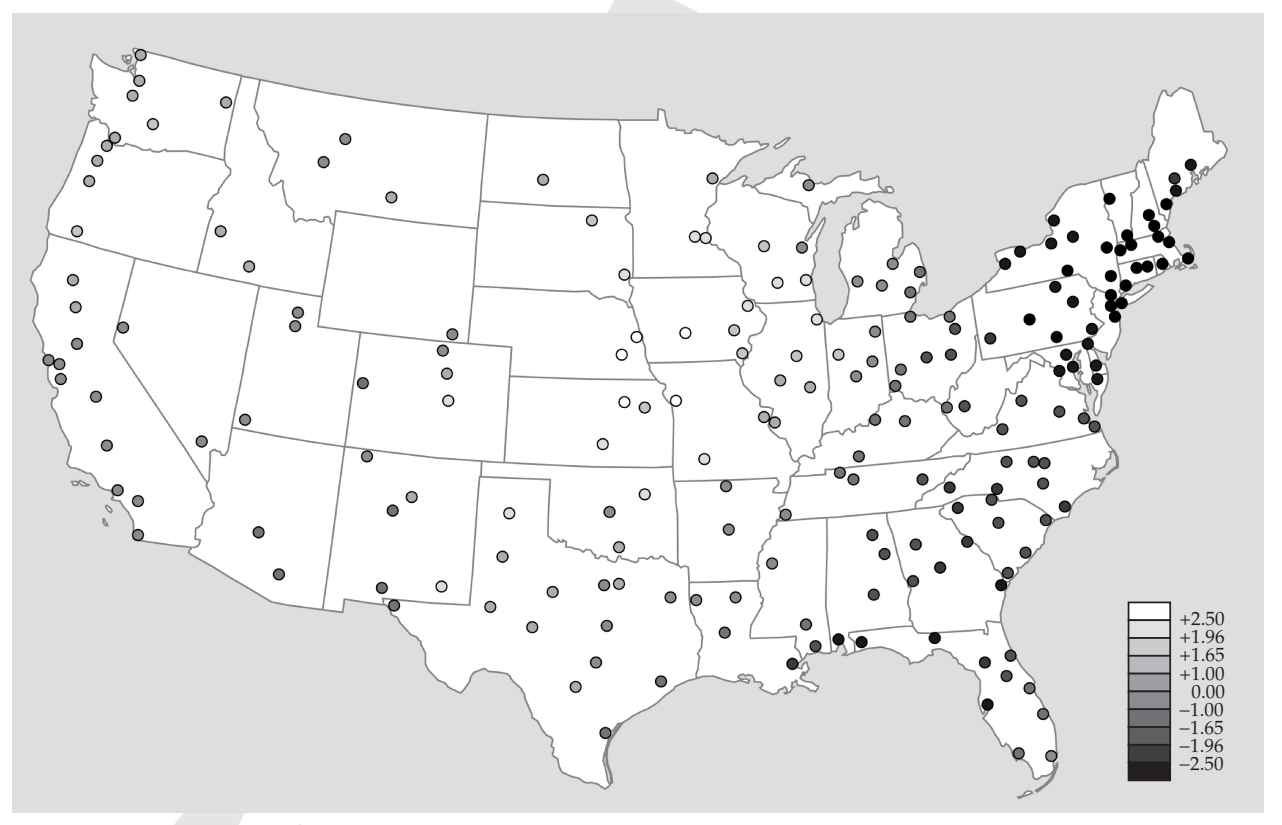

Figure 3 Modal not contraction Getis-Ord $G i^{*} z$ scores

measures cluster in the east, the focal areas for do not contraction and modal not contraction are in the northeast, whereas the focal area for be not contraction is in the southeast. The focal areas for the high-value clusters are in the Midwest for all three variables, especially the western Midwest and the northern Plains, as well as the Pacific Northwest for do not contraction. 


\section{Discussion}

The study found that not contraction is regionally patterned in written Standard American English, with letters to the editor from the western United States exhibiting a higher rate of not contraction than letters from the eastern United States. It is surprising that a contrast between the east and the west has been identified by the autocorrelation analysis, as previous surveys have found that the contrast between the north and the south is far stronger in American English (Kurath, 1949; Carver, 1987; Labov et al., 2006). The east-west contrast is also unusual because it groups the Midwest with the west; the Midwest is generally considered to be an extension of eastern dialect regions. The results of this study show that, in terms of not contraction, the language of the Midwest is distinct from the language of the east coast. This finding makes sense intuitively: when asked, Americans identify a distinct Midwest dialect region (Preston, 2002), and the Midwest and the northeast can also be distinguished on historical, cultural, geographical, and political grounds (Zelinsky, 1973).

The general finding that regional linguistic variation exists in written Standard English is also an important result because it challenges the common assumption that sociolinguistic variation, including regional linguistic variation, does not exist in written standard language (Schneider, 2002). The results of this study show that this assumption is false: Regional linguistic variation does exist in written Standard English. More generally, this finding implies that regional linguistic variation is more common than has been previously assumed. If regional linguistic variation exists in written Standard English, it seems likely that regional linguistic variation exists across the range of English registers, not only in the spoken vernacular. The statistical approach to data analysis described here, particularly when coupled with a corpus-based approach to data collection, constitutes a method for identifying regional variation across a range of registers, especially in registers where regional patterns may not be as strong as they are in the spoken vernacular. This was certainly the case in the present study: If the autocorrelation statistics had not been employed, it would have been difficult to convincingly identify regional patterns in not contraction.

In addition to these important findings, the study also demonstrates how measures of spatial autocorrelation can be used to analyze regional linguistic variation in the values of an individual linguistic variable. In essence, the spatial autocorrelation statistics allow for regional patterns to be identified in the spatial distribution of a linguistic variable in the same way as logistic regression allows for social patterns to be identified in the social distribution of a linguistic variable. Overall, the advantages of the statistical approach are clear. It allows for an objective, unbiased, and replicable analysis of regional linguistic variation to be conducted, where regional patterns are identified based on significance testing as opposed to the judgment of the dialectologist. This not only allows for the presence of obvious patterns to be confirmed but it also allows for patterns to be identified that may have been overlooked by a subjective analysis. Arguably, identifying a variable that exhibits a regional pattern and describing this pattern is the most basic form of analysis in regional dialectology; however, until now, there has been no acceptable statistical method for conducting this analysis. In modern dialectology, the analysis of an individual linguistic variable is usually accomplished through the subjective examination of a map plotting the raw values of the variable. In modern dialectometry, the analysis of individual linguistic variables is usually ignored. The two measures of spatial autocorrelation presented here provide a statistically justified method for identifying regional linguistic patterns in the values of an individual linguistic variable. 
SEE ALSO: Applied Corpus Linguistics; Corpora: English-Language; Corpus Analysis in Dialectology; Corpus Linguistics: Quantitative Methods; Quantitative Methods; Variables

\section{References}

Ashby, W. J. (1981). The loss of the negative particle ne in French: A syntactic change in progress. Language, 57, 674-87.

Carver, C. M. (1987). American regional dialects. Ann Arbor: University of Michigan Press.

Cedergren, H., \& Sankoff, D. (1974). Variable rules: Performance as a statistical reflection of competence. Language, 50, 333-55.

Cliff, A. D., \& Ord, J. K. (1973). Spatial autocorrelation. London, England: Pion.

Cliff, A. D., \& Ord, J. K. (1981). Spatial processes: Models and applications. London, England: Pion. Fischer, J. L. (1958). Social influence in the choice of a linguistic variant. Word, 14, 47-56.

Gilliéron, J. (1902-10). Atlas linguistique de la France (13 vols.). Paris, France: Champion.

Goebl, H. (1982). Dialektometrie: Prinzipien und Methoden des Einsatzes der numerischen Taxonomie im Bereich der Dialektgeographie. Vienna, Austria: Verlag der Osterreichischen Akademie der Wissenschaften.

Goebl, H. (2006). Recent advances is Salzburg dialectometry. Literary and Linguistic Computing, 21, 411-35.

Kurath, H. (1949). Word geography of the eastern United States. Ann Arbor: University of Michigan Press.

Kurath, H., Hansen, L., Bloch, B., \& Bloch, J. (1939-43). Linguistic atlas of New England. Providence, RI: Brown University Press.

Kurath, H., \& McDavid, R. I. (1961). The pronunciation of English in the Atlantic States. Ann Arbor: University of Michigan Press.

Labov, W. (1963). The social motivation of sound change. Word, 19, 273-309.

Labov, W. (1966). The social stratification of English in New York City. Washington, DC: Center for Applied Linguistics.

Labov, W. (1969). Contraction, deletion, and inherent variability of the English copula. Language, $45,715-62$.

Labov, W. (1972). Sociolinguistic patterns. Philadelphia: University of Pennsylvania Press.

Labov, W., Ash, S., \& Boberg, C. (2006). Atlas of North American English: Phonetics, phonology, and sound change. New York, NY: De Gruyter.

Moran, P. A. P. (1948). The interpretation of statistical maps. Journal of the Royal Statistical Society, Series B, 37, 243-51.

Nerbonne, J., Heeringa, W., Van den Hout, E., van der Kooi, P., Otten, S., \& van de Vis, W. (1996). Phonetic distance between Dutch dialects. In G. Durieux, W. Daelemans, \& S. Gillis (Eds.), Papers from the sixth CLIN meeting. Antwerp, Belgium: University of Antwerp.

Nerbonne, J., \& Kleiweg, P. (2003). Lexical distance in LAMSAS. Computers and the Humanities, $37,339-57$.

Nerbonne, J., \& Kleiweg, P. (2007). Toward a dialectological yardstick. Journal of Quantitative Linguistics, 14, 148-66.

Odland, J. D. (1988). Spatial autocorrelation. Newbury Park, CA: Sage.

Ord, J. K., \& Getis, A. (1995). Local spatial autocorrelation statistics: Distributional issues and an application. Geographical Analysis, 27, 286-306.

Pederson, L., McDaniel, S. L., \& Adams, C. M. (1986-93). Linguistic atlas of the Gulf States (7 vols.). Athens, GA: University of Georgia Press.

Preston, D. (2002). Language with attitude. In J. K. Chambers, P. Trudgill, \& N. Schilling-Estes (Eds.), The handbook of language variation and change (pp. 40-66). Malden, MA: Blackwell.

Sankoff, D., \& Labov, W. (1979). On the uses of variable rules. Language in Society, 8, 189-222. 


\section{SOCIOLINGUISTICS: QUANTITATIVE METHODS}

Schneider, E. (2002). Investigating variation and change in written documents. In J. K. Chambers, P. Trudgill, \& N. Schilling-Estes (Eds.), The handbook of language variation and change (pp. 67-96). Malden, MA: Blackwell.

Séguy, J. (1971). La relation entre la distance spatiale et la distance lexicale. Revue de linguistique romane, 35, 335-57.

Séguy, J. (1973). La dialectométrie dans l'atlas linguistique de la Gascogne. Revue de linguistique romane, 37, 1-24.

Wenker, G. (1881). Sprachatlas des deutschen Reichs. Marburg, Germany: Elwert.

Wolfram, W. (1969). A sociolinguistic description of Detroit negro speech. Washington, DC: Center for Applied Linguistics.

Wolfram, W. (1991). The linguistic variable: Fact and fantasy. American Speech, 66, 22-32.

Zelinsky, W. (1973). The cultural geography of the United States. Englewood Cliffs, NJ: PrenticeHall.

\section{Suggested Readings}

Chambers, J. K., \& Trudgill, P. (1998). Dialectology (2nd ed.). Cambridge, England: Cambridge University Press.

Chambers, J. K., Trudgill, P., \& Schilling-Estes, N. (Eds.). (2002). The handbook of language variation and change. Malden, MA: Blackwell.

Paolillo, J. (2002). Analyzing linguistic variation: Statistical models and methods. Stanford, CA: CSLI Publications.

Tagliamonte, S. (2006). Analysing sociolinguistic variation. Cambridge, England: Cambridge University Press. 